\title{
DESENVOLVIMENTO DE NOVOS MATERIAIS CERÂMICOS A PARTIR DE RESÍDUOS DE LAPIDÁRIOS
}

\author{
GUERRA, R.F. ${ }^{1}$ REIS, A.B.dos ${ }^{2}$, VIEIRA. F. T. ${ }^{3}$ \\ ${ }^{1}$ Universidade Federal dos Vales Jequitinhonha e Mucuri, Departamento de Engenharia Química \\ ${ }^{2}$ Universidade Federal dos Vales Jequitinhonha e Mucuri, Departamento de Engenharia Química \\ E-mail para contato: arlete.reis@ict.ufvjm.edu.br \\ ${ }^{3}$ Universidade Federal dos Vales Jequitinhonha e Mucuri, Departamento de Engenharia Química \\ E-mail para contato: flaviana.tavares@ufvjm.edu.br
}

\begin{abstract}
RESUMO: O presente trabalho tem por objetivo apresentar os resultados relativos a formulação de massas para revestimento cerâmico variando a quantidade de pó de lapidário. As matérias-primas, massa argilosa e pó de lapidário provenientes da região do Vale do Mucuri foram inicialmente submetidos a ensaios de caracterização mineralógica, química e física. Foram preparados corpos de prova para sinterização nas temperaturas de 850,950 e $1100^{\circ} \mathrm{C}$. As propriedades avaliadas foram com o objetivo de apresentar é discutir resultados relativos a um estudo preliminar sobre difusão em materiais cerâmicos nesse material.
\end{abstract}

\section{INTRODUÇÃO}

O Vale Mucuri, em Minas Gerais, segundo o artigo Pólos de Gemas e Jóias do Estado de Minas Gerais, é assentado em uma das maiores províncias gemológicas do mundo, dadas sua extensão e diversidade de gemas que vão desde o diamante até a ametista e o citrino. Tal região vem sendo explorada por mais de 50 anos e as principais gemas extraídas são: água-marinha, quartzo rosa, topázio e turmalina. O segmento de lapidação é uma de suas mais importantes atividades econômicas e, segundo um levantamento realizado pelo Ministério da Ciência e Tecnologia, na região existe cerca de 300 microempresas nas áreas de lapidação e comercialização. Grande parte do material a ser lapidado é processado em Teófilo Otoni. Este processo gera rejeitos minerais como o pó de pedra. De acordo com o SERVIÇO GEOLÓGICO DO BRASIL (2013) esse danifica o meio ambiente causando poluição do ar e impactos na paisagem. A poluição do ar ocorre principalmente nas etapas de lavra, através dos desmontes, transporte de materiais e beneficiamento, já a remoção da cobertura vegetal e a disposição dos rejeitos causam grandes impactos na paisagem. A adoção de alternativa de aproveitamento desse resíduo poderá agregar valor a esse material para uso industrial. Designar um destino nobre para os resíduos, sempre que pertinente, constitui na atualidade, um grande desafio para os pesquisadores que atuam no setor PERREIRA (2002). Neste caso, a indústria cerâmica se destaca pela facilidade em co-processar resíduos e um dos itens principalmente aqueles com propriedades físico-químicas que se adequam ás particularidades do processo produtivo, podendo possibilitar vantagens à indústria e ao processo, tais como, economia, redução do consumo de energia entre outras. 


\section{OBJETIVO}

Desenvolver materiais de cerâmicos utilizando pó de pedras semi-preciosas proveniente de lapidários do Vale do Mucuri;

Avaliar o processo difusivo dos materiais cerâmicos produzidos em escala laboratorial;

Realizar análise comparativa do processo difusivo entre o material cerâmico obtido comercialmente e o material cerâmico desenvolvido em laboratório;

\section{METODOLOGIA}

\section{Obtenção e Preparo das amostras}

Após a coleta das matérias-primas o pó de lapidário (Figura 2) e o pó de argila (Figura 3) foram inicialmente secas em estufa a $110^{\circ} \mathrm{C}$ em equipamento Ethik Techonology, modelo $402-5 \mathrm{~d}$ com potencia 1000w durante um tempo de 30 minutos depois desagregadas com pilão manual e submetida a peneiramento em peneira ABNT 35\#. A distribuição de tamanho de partículas foi determinada de acordo com a norma NBR 7181, a qual combina técnicas de peneiramento e de sedimentação.

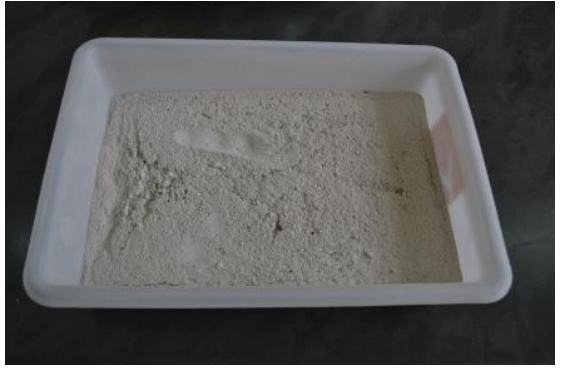

Figura 2 - Pó de Lapidário seco. Fonte: UFVJM, 13/11/2013.

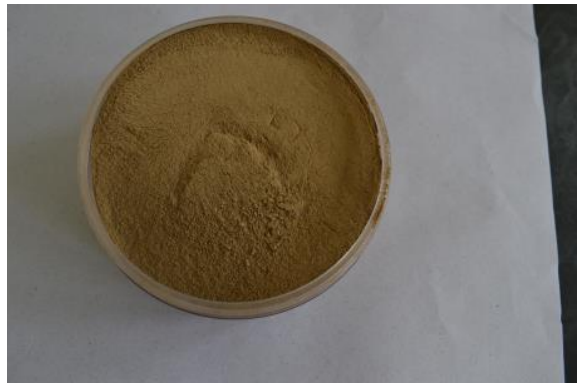

Figura 3 - Argila seca. Fonte: UFVJM, 13/11/2013.

A composição química das matérias-primas foi determinada por fluorescência de raios X (FRX) em equipamento SHIMADZU EDX-720. A composição mineralógica qualitativa foi obtida por difração de raios X (DRX), em equipamento SHIMADZU RXD 6000, operando com radiação $\mathrm{Cu}-\mathrm{K} \alpha$ e $2 \theta$ variando de $5^{\circ}$ a $60^{\circ}$. 
As amostras foram preparadas nas composições conforme a tabela 1:

Tabela 1 - Composição das Amostras.

\begin{tabular}{|r|c|c|}
\hline \multicolumn{3}{|c|}{ Composição das Amostras } \\
\hline Amostras & \% de Argila & \% de Pó de Pedra \\
\hline AM 1 & 100 & 0 \\
\hline AM 2 & 95 & 5 \\
\hline AM 3 & 90 & 10 \\
\hline AM 4 & 85 & 15 \\
\hline AM 5 & 80 & 20 \\
\hline AM 6 & 75 & 25 \\
\hline
\end{tabular}

Estas misturas foram homogeneizadas a seco em uma misturadora durante 15 minutos obtendo uma massa com ótima plasticidade.

A plasticidade das composições foi determinada de acordo com as normas técnicas ABNT NBR 6459 e ABNT NBR 7180 por meio da determinação dos limites de Atterberg. $\mathrm{mm}^{3}$.

Os corpos de prova foram conformados por extrusão manual nas dimensões 50 x 50 x 10

Os corpos de prova inicialmente foram secos em temperatura ambiente por $24 \mathrm{~h}$ e colocados em estufa a $110^{\circ} \mathrm{C}$ até alcançarem peso constante.

A queima foi realizada em uma mufla nas temperaturas de 850,950 e $1100{ }^{\circ} \mathrm{C}$, com 120 min de patamar com taxa de aquecimento/resfriamento $2{ }^{\circ} \mathrm{C} / \mathrm{min}$.

As propriedades dos corpos de provas foram determinadas por analises de micro estrutura de varredura MEV retração linear de queima, absorção de água e tensão de ruptura à flexão. 


\section{RESULTADOS}

\section{Granulometria}

Nas (Figuras 8, 9,10, 11 e 12) é possível observar as diferentes granulometrias presente do pó de pedra.

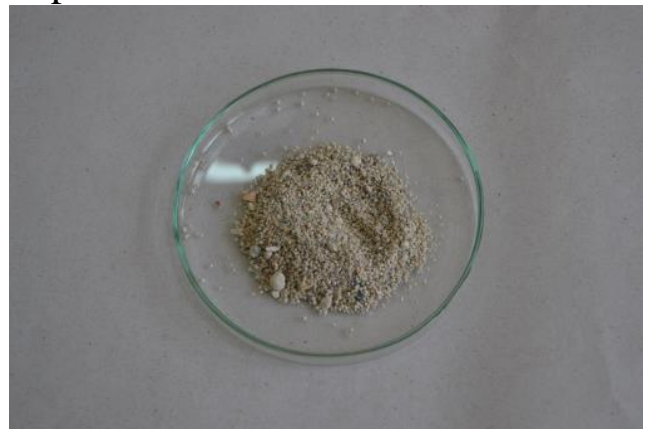

Figura 8 - Peneira de 35\#.

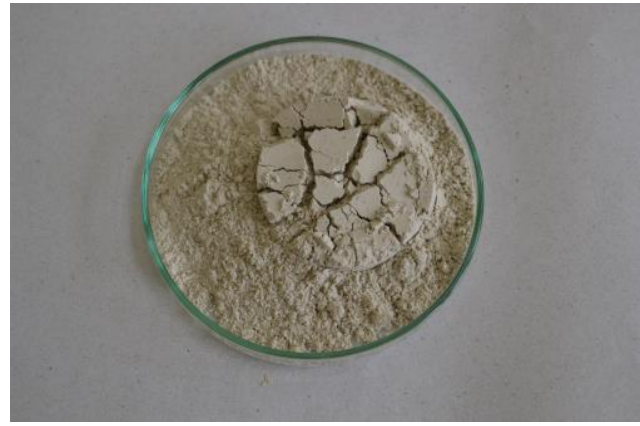

Figura 1 - Peneira de 50\#.

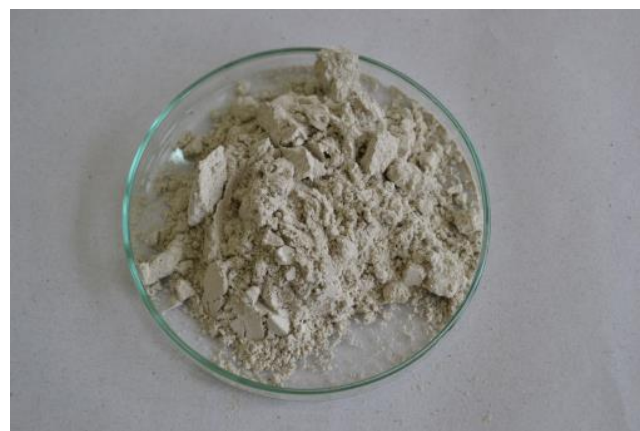

Figura 2 - Peneira de 70\#.

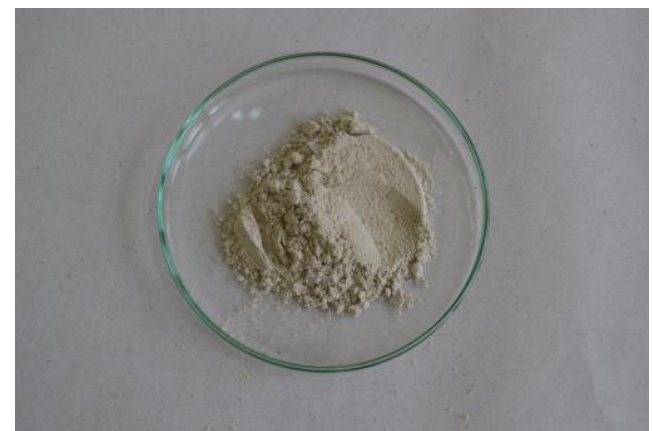

Figura 3 - Peneira de 100\#.

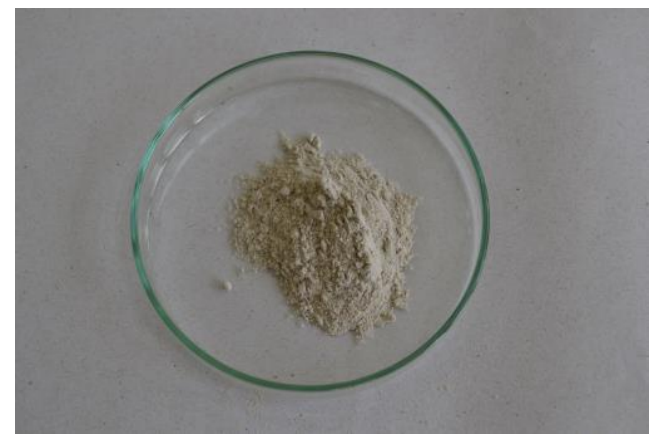

Figura 4 - Base das peneiras granulometria maior que $100 \#$.

A tabela 2 informa a característica física do pó de lapidário, podendo verificar a porcentagem de cada granulometria presente na mistura. Os resultados são demonstrados em mesh granulometria característica de cada peneira. 
Tabela 2-Características Físicas

Do Pó de Lapidário.

\begin{tabular}{|c|c|}
\hline \multicolumn{2}{|c|}{ Composição } \\
\hline$\#$ & $\begin{array}{c}\text { \% Porcentagem em } \\
\mathbf{2 0 0 g}\end{array}$ \\
MESH & $16,6 \mathrm{~g}$ \\
\hline $35 \#$ & $72,4 \mathrm{~g}$ \\
\hline $50 \#$ & $77,5 \mathrm{~g}$ \\
\hline $70 \#$ & $17,5 \mathrm{~g}$ \\
\hline $100 \#$ & $16 \mathrm{~g}$ \\
\hline Base & \\
\hline
\end{tabular}

\section{Fluorescência de Raios X}

As figuras 11 e 12 apresentam os espectros do pó de pedra e da argila respectivamente.
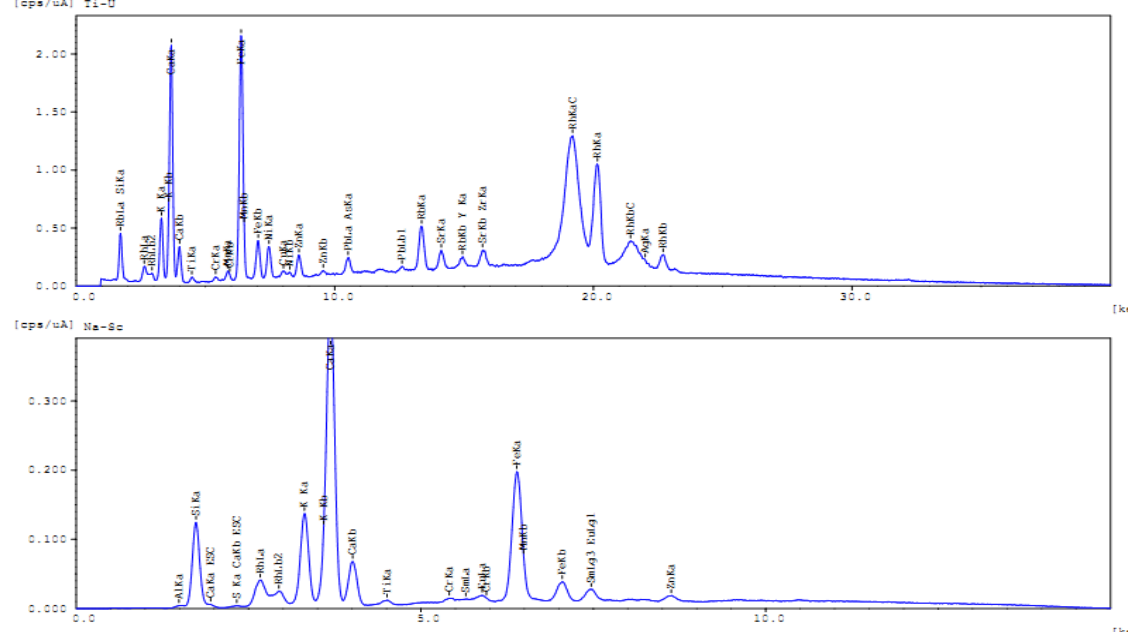

Figura 5 - Espectrometria por Fluorescência de Raios X do Pó de Pedra.
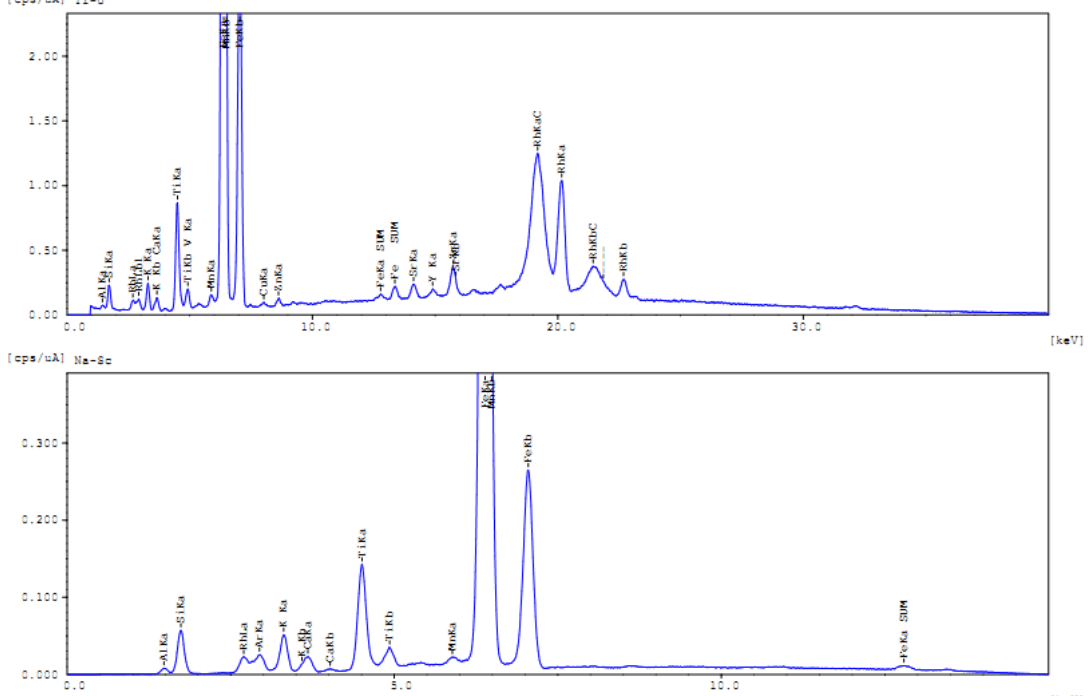
Figura 7 - Espectrometria por Fluorescência de Raios X da Argila.

A proporção da composição elementar de cada elemento presente no pó de pedra e na argila são estabelecidas respectivamente conforme a tabela 3.

Tabela 3 - Proporção Elementar
\begin{tabular}{|c|c|c|c|}
\hline \multicolumn{4}{|c|}{ Proporção Elementar } \\
\hline \hline Pó de Lapidario & $\%$ & Argila & $\%$ \\
\hline $\mathrm{Si}$ & 59 & $\mathrm{Si}$ & 39,5 \\
\hline $\mathrm{Al}$ & 17 & $\mathrm{Al}$ & 39 \\
\hline $\mathrm{Ca}$ & 14,5 & $\mathrm{Fe}$ & 16,5 \\
\hline $\mathrm{K}$ & 6 & $\mathrm{~K}$ & 2 \\
\hline $\mathrm{Fe}$ & 3 & $\mathrm{Ti}$ & 2 \\
\hline Outros & 0,5 & Outros & 1 \\
\hline
\end{tabular}

\section{Microscopia Eletrônica de Varredura}

O processo de difusão que ocorre em sistemas de silicatos é a interdifusão entre sólidos, nas figuras 13 e 14 observa-se que a $1100^{\circ} \mathrm{C}$ houve o processo de interdifusão. Do resultado das análises concluiu-se que houver a interdifusão indicada pelas camadas de interdifusão que podem ser vistas pelas imagens de MEV, uma coloração mais clara entre as áreas escuras e brancas.

Nas figuras 15 e 16 foi realizado testes de analise elementar em diferentes pontos do material, para determinas os elementos presentes nos pontos indicado no material, as concentrações detectadas são observadas na tabela 4, concluindo que houve a interdifusão.

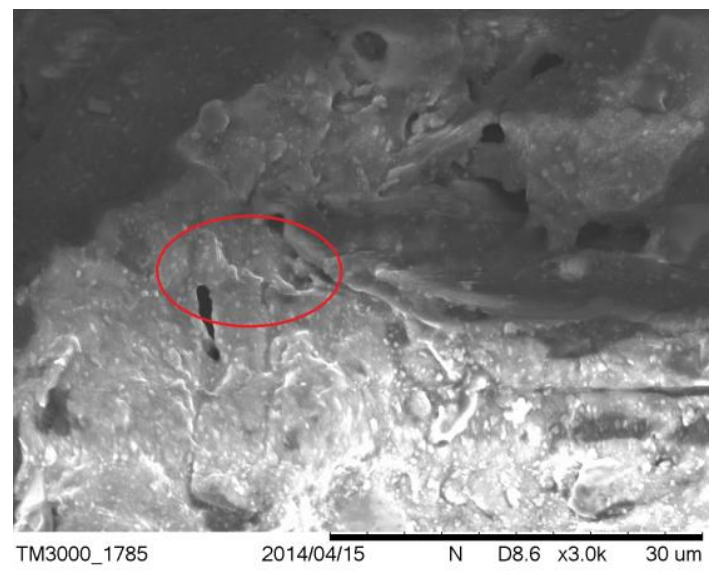

Figura 13 - AM25 Aumentada 3000x.

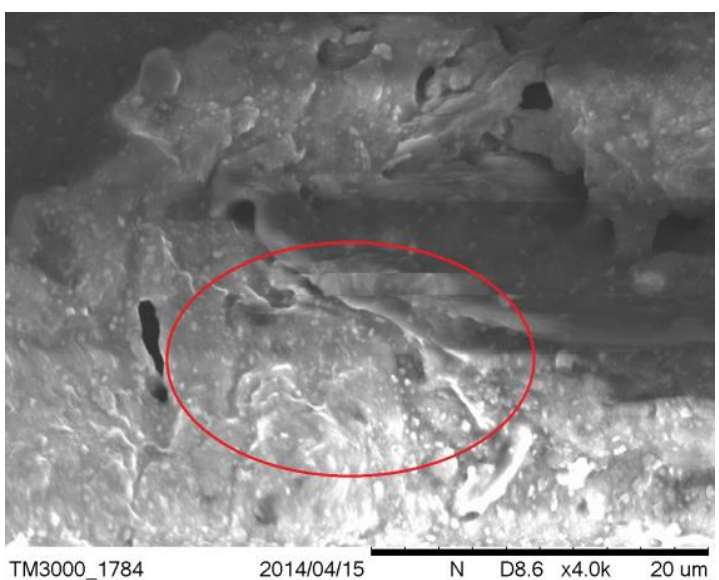

Figura 14 - AM25 Aumentada 4000x. 


\section{Electron Image}

Image Width: $41.2 \mu \mathrm{m}$

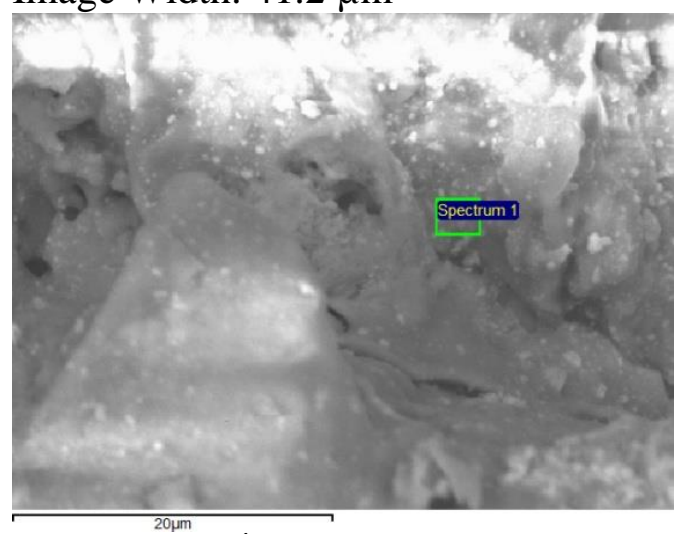

Figura 15 - Área da analise elementar da amostra AM251100

\section{Electron Image}

Image Width: $164.6 \mu \mathrm{m}$

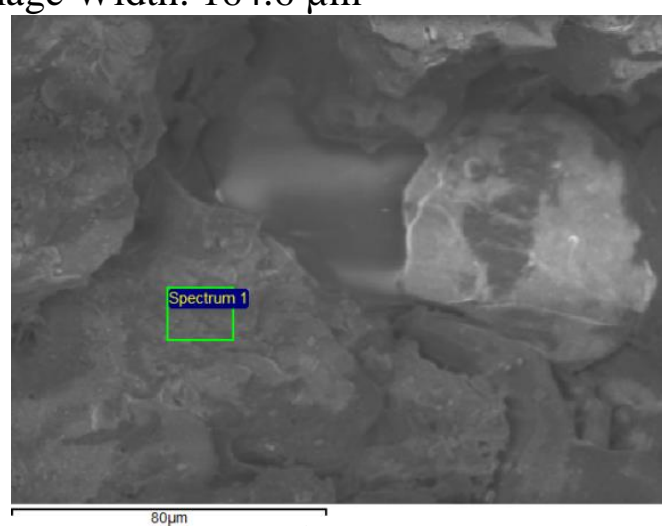

Figura 16 - Área da analise elementar da amostra AM25110

Tabela 4 - Composição nos pontos das figuras 15 e 16

\begin{tabular}{|c|c|c|c|}
\hline \multicolumn{4}{|c|}{ Elementos } \\
\hline \hline \multicolumn{2}{|c|}{ Figura 15 } & \multicolumn{2}{c|}{ Figura 16 } \\
\hline $\mathrm{Al} 2 \mathrm{O} 3$ & $4 \%$ & $\mathrm{Al} 2 \mathrm{O} 3$ & $12 \%$ \\
\hline $\mathrm{SiO} 2$ & $4,00 \%$ & $\mathrm{SiO} 2$ & $20 \%$ \\
\hline $\mathrm{FeO}$ & $65 \%$ & $\mathrm{FeO}$ & $20 \%$ \\
\hline $\mathrm{O}$ & $26 \%$ & $\mathrm{O}$ & $41 \%$ \\
\hline Outros & $1 \%$ & Outros & $7 \%$ \\
\hline
\end{tabular}

\section{CONCLUSÃO}

A partir dos resultados obtidos pela microscopia eletrônica de varredura e comparados com as analises feitas em telhas e tijolos observou-se a ocorrência do processo de interdifusão e de sua possibilidade de aplicabilidade na indústria cerâmica de construção civil, tendo os resultados obtidos comparados com os materiais presentes no mercado de construção civil. 


\section{REFERÊNCIAS}

APRENDENDO A EXPORTAR - Gemas e Joias. Disponível em: http://www.aprendendoaexportar.gov.br/gemasejoias/html/sobre/arranjos_produtivos_locais.html . Acessado em 19/09/2013.pg 1.

O SERVIÇO GEOLÓGICO DO BRASIL. Disponível em: http://www.cprm.gov.br/publique/media/art_quartzito_Faleiro.pdf. P. 2,3.

PEREIRA, R.L. 2002. Resíduos Sólidos Industriais: Uma Fonte Alternativa na Elaboração de Materiais Cerâmicos de Baixa Densidade. Tese de Mestrado em Engenharia de Materiais e Processos Avançados - Universidade do Estado de Santa Catarina, Centro de Ciências Tecnológicas - CCT, 106p.

ASSOCIAÇÃO BRASILEIRA DE NORMAS TÉCNICAS - ABNT NBR 7181: Determinação da Análise Granulométrica de Solos, Rio de Janeiro, RJ (1984).

ASSOCIAÇÃO BRASILEIRA DE NORMAS TÉCNICAS - ABNT NBR 6459: Determinação do limite de plasticidade de solos, Rio de Janeiro, RJ (1984).

ASSOCIAÇÃO BRASILEIRA DE NORMAS TÉCNICAS - ABNT. NBR 7180: Determinação do limite de liquidez de solos, Rio de Janeiro, RJ (1984). 